\title{
ESPACIALIDADE DO SER-PROFISSIONAL-DE-ENFERMAGEM NO MUNDO DO CUIDADO À CRIANÇA QUE TEM CÂNCER ${ }^{a}$
}

\author{
Spaciality of being-nursing-professional in the world of caring to children who has cancer \\ Especialidad del ser profesional de enfermería en el mundo del cuidado al niño que tiene \\ cáncer
}

Cintia Flores Mutti

Stela Maris de Mello Padoin²

Cristiane Cardoso de Paula ${ }^{3}$

\section{RESUMO}

Objetivo: compreender o significado para equipe de enfermagem de cuidar de crianças que têm doença oncológica avançada, cuja enfermidade não responde mais aos tratamentos curativos. Método: Investigação fenomenológica heideggeriana. Etapa de campo desenvolvida no período de dezembro/2010 a março/2011, com 15 profissionais de enfermagem no Hospital Universitário de Santa Maria, Rio Grande do Sul, Brasil. Resultados: 0 profissional de enfermagem expressa que, no cotidiano de cuidado à criança que tem câncer, tem que separar o profissional do emocional. Descreve o seu dia a dia dentro e fora do hospital. Com o tempo, aprende a separar o trabalho da vida pessoal. Conclusões: Aponta a necessidade do desenvolvimento de estratégias de ação multiprofissional entre a equipe que cuida, considerando que também precisa ser cuidada.

Palavras-chave: Enfermagem oncológica. Criança. Neoplasias. Cuidados paliativos.

\begin{abstract}
Objective: to comprehend the meaning of taking care of children who have an advanced cancer that no longer responds to curative treatments for nursing staff. Methods: heideggerian phenomenological research. Field step developed from December/2010 to March/2011 with 15 nursing professionals at University Hospital of Santa Maria, Rio Grande do Sul, Brazil. Results: Nursing professional expresses that, in daily care to children who have cancer, they have to separate professional from emotional. They describe their daily routine inside and outside the hospital. With time, they learn how to separate work from personal life. Conclusions: It points out the need of developing strategies of multi-professional actions among the team that takes care of, considering that it also needs to be taken care of.
\end{abstract}

Keywords: Oncologic Nursing. Child. Neoplasm. Palliative Care.

\section{Resumen}

Objetivo: comprender el significado para el equipo de enfermería de atención a niños que tienen enfermedad oncológica avanzada, cuya enfermedad no responde más a los tratamientos curativos. Método: Investigación fenomenológica heideggeriana. Etapa de campo desarrollada en el período de diciembre/2010 a marzo/ 2011, con 15 profesionales de enfermería en el Hospital Universitario de Santa Maria, Rio Grande do Sul, Brasil. Resultados: El profesional de enfermería expresa que, en el cotidiano de cuidado al niño que tiene cáncer, tiene que separar el profesional del emocional. Describe su rutina dentro y fuera del hospital. Con el tiempo aprende a separar el trabajo de la vida profesional. Conclusiones: Apunta la necesidad del desarrollo de estrategias de acción multiprofesional entre el equipo que cuida, considerando que también necesita atención.

Palavras clave: Enfermería Oncológica. Niño. Neoplasias. Cuidados paliativos.

\footnotetext{
Enfermeira. Especialista em Enfermagem em Oncologia pelo INCA-RJ. Mestranda do Programa de Pós-graduação em Enfermagem da Universidade Federal de Santa Maria (UFSM), bolsista CAPES. Membro do Grupo de Pesquisa Cuidado à Saúde das Pessoas, Famílias e Sociedade (PEFAS). Santa Maria-RS. Brasil. E-mail: cfmutti@hotmail.com; ${ }^{2}$ Enfermeira. Doutora em Enfermagem. Professora Adjunta do Departamento de Enfermagem da Universidade Federal de Santa Maria. Líder do Grupo de Pesquisa PEFAS. Santa Maria-RS. Brasil.E-mail: stelamaris_padoin@hotmail.com; ${ }^{3}$ Enfermeira. Especialista em Enfermagem Pediátrica. Doutora em Enfermagem. Professora Adjunta do Departamento de Enfermagem da Universidade Federal de Santa Maria. Líder do Grupo de Pesquisa PEFAS. Santa Maria-RS. Brasil. E-mail: cris_depaula1@hotmail.com
} 


\section{INTRODUÇÃO}

No âmbito mundial, o câncer representa 0,5 a 3\% de prevalência entre as crianças, se comparadas à população em geral. No Brasil, a incidência se situa próximo de 3\%, o que corresponde a 9.890 casos de tumores pediátricos por ano. 0 câncer aparece entre as cinco principais causas de óbitos desde os primeiros anos de vida'.

A proposta de política pública brasileira para diagnóstico precoce de câncer nas crianças e nos adolescentes que têm câncer se justifica pela expressão da mortalidade proporcional demonstrada nesse grupo. A sobrevida dessas crianças tem melhorado devido à implantação de centros especializados e à implementação dos já existentes. Sua cura ultrapassa a faixa de $70 \%$ dos casos $^{2}$.

A assistência em oncologia desenvolve-se pelo cuidado preventivo, curativo e paliativo. Em relação à prevenção primária, não existem medidas efetivas para impedir o desenvolvimento de câncer na faixa etária pediátrica. $\mathrm{Na}$ prevenção secundária, a detecção precoce é a principal estratégia, pois, quando o diagnóstico é feito em fases iniciais, permite um tratamento menos agressivo e mais efetivo, com maiores possibilidades de cura e menores sequelas da doença ou do tratamento ${ }^{3}$.

A terapêutica curativa envolve as fases de diagnóstico, modalidades de tratamento e controle. Essa terapêutica tem dois objetivos: aumentar as taxas de sobrevida, minimizando os efeitos tardios do tratamento, e reintegrar a criança na sociedade com qualidade de vida ${ }^{4}$. Conta com as seguintes modalidades: quimioterápica, radioterápica, cirúrgica, transplante de células-tronco hematopoiéticas.

Quando não houver sucesso no tratamento e a criança for diagnosticada como fora de possibilidades terapêuticas de cura, a transição do seguimento clínico para o cuidado paliativo deve ser gradual. Faz-se imprescindível uma comunicação clara, por meio de uma relação de confiança, considerando os aspectos emocionais e respeitando a criança e a família-5.

No âmbito da saúde, os cuidados paliativos surgem como a condição básica para resgatar o respeito e a dignidade daquele que tem doença avançada 6 . Diante dessa assistência especializada, destaca-se a importância de uma equipe de saúde multiprofissional, com habilidades para: avaliar as condições da criança, desenvolver um plano individualizado de cuidados e acompanhar os resultados do tratamento. Vislumbra-se integrar a objetividade (técnicas) e a subjetividade (apoio), tanto para a criança quanto para a sua família?.

A neoplasia na infância suscita mudança repentina e drástica na rotina de vida, desde o diagnóstico e 0 tratamento até o desfecho imprevisível da cura ou impossibilidade desta. Isso causa sofrimento à criança, à sua família e aos profissionais ${ }^{5,8}$. A família se vê diante da necessidade de se reorganizar para enfrentar os desafios resultantes da doença, como problemas econômicos, bem como da representação social negativa do câncer ${ }^{5,9-10}$.

A assistência em oncologia requer do profissional de saúde uma prática resolutiva, seja qual for a situação da doença vivenciada pela criança e seus desdobramentos no cotidiano familiar. Desse modo, mostra-se a necessidade de rever dinâmicas assistenciais e práticas no cuidar em pediatria oncológica, a partir de uma visão holística.

Como integrante da equipe multiprofissional, a(0) enfermeira(o) está presente nas diferentes etapas de cuidado, desde a prevenção, o diagnóstico, os tratamentos prolongados, até o cuidado paliativo. Quando a doença avança e os tratamentos curativos não são viáveis, essa criança necessita permanecer em acompanhamento, na maioria das vezes, em unidades de internação, ambulatorial ou de tratamento intensivo. 0 cuidado de enfermagem envolve o controle da dor e demais sinais e sintomas, da ansiedade e depressão, além do compartilhamento das decisões do cuidar com a criança e sua família ${ }^{10}$.

A atuação da equipe de enfermagem diante da complexidade do cuidado a essas crianças compreende a necessidade de empenho da equipe de saúde, por meio do trabalho interdisciplinar. Contempla atender a unidade familiar em suas possibilidades, incertezas, diversidades e imprevisibilidades, perante a instabilidade do quadro clínico da criança e a proximidade da morte ${ }^{5,11}$.

A criação de vínculo entre os profissionais de enfermagem e a criança torna-se inevitável, devido ao longo tempo de acompanhamento. 0 convivio das hospitalizações possibilita um relacionamento mais próximo com a criança e a família, compartilhando experiências boas e ruins do dia a dia, bem como emoções e sentimentos ${ }^{5,12}$.

Dentre essas experiências, destacam-se 0 enfrentamento da morte dessas crianças e o suporte às suas famílias. A aceitação da morte por parte do paciente, família e equipe se torna mais resolutiva com os cuidados paliativos, 0 que contribui para a morte amena. Nessa fase terminal, o enfermeiro é o profissional de referência para 0 apoio às necessidades dos pais e pacientes ${ }^{13-16}$.

Diante dessa problemática do câncer infantil, é apresentada a questão: Como se sentem os profissionais de enfermagem que vivenciam o cuidado à criança que tem doença oncológica avançada? E o objetivo: compreender o significado para a equipe de enfermagem de cuidar de crianças que têm doença oncológica avançada, cuja enfermidade não responde mais aos tratamentos curativos.

\section{MÉTODO}

Trata-se de uma investigação de natureza qualitativa, com abordagem fenomenológica e referencial teórico-filosófico-metodológico de Martin Heidegger ${ }^{17}$. Entende-se que é necessário e opor tuno compreender os sentimentos, as emoções e os significados que o ser 
humano confere às situações experienciadas e vivenciadas ${ }^{18}$

Essa abordagem busca desvelar, no objeto de estudo, a maneira como ele é em si mesmo - como é o cuidado por meio do seu significado -, e não apenas o que é - o que é o cuidado - ou seja, um saber do fenômeno e não somente sobre ele. Para tanto, suspende o conhecimento factual - 0 que já se sabe sobre os fatos - em busca da compreensão existencial do fenômeno.

Desse modo, possibilita lançar um olhar ao profissional de enfermagem que cuida da criança com doença oncológica avançada em seu mundo próprio existencial. Isso é possível por meio da intersubjetividade entre pesquisador e sujeito da pesquisa, na busca dos significados que os próprios sujeitos atribuem à sua vivência, expressos em suas próprias palavras, a partir do mundo da vida cotidiana, de sua bagagem de conhecimentos e de sua historicidade. Nesta pesquisa, o mundo da vida refere-se especificamente ao cotidiano assistencial hospitalar de cuidado de enfermagem à criança que tem câncer.

A etapa de campo da pesquisa foi desenvolvida no Hospital Universitário de Santa Maria (HUSM/RS) em três unidades: 0 centro de tratamento à criança e ao adolescente com câncer, a unidade de terapia intensiva pediátrica e 0 ambulatório de quimioterapia; no período de dezembro de 2010 a março de 2011.

Os participantes foram os profissionais das equipes de enfermagem, conforme os critérios de inclusão: 1) desenvolver ações de cuidado às crianças com doença oncológica avançada, cuja enfermidade não responde mais aos tratamentos curativos; e 2) integrar o quadro de pessoal (enfermeiro, técnico ou auxiliar de enfermagem) de uma das três unidades supracitadas. 0 critério de exclusão foi: estar afastado do trabalho, em licença ou em férias. 0 número de participantes não foi predeterminado, visto que a etapa de campo, desenvolvida concomitante à análise, mostrou o quantitativo de entrevistas necessário para responder ao objetivo da pesquisa, ao apontar a suficiência de significados expressos nas falas dos profissionais de enfermagem ${ }^{19}$. Totalizou-se com 15 profissionais de enfermagem.

Para a produção dos dados foi realizada a entrevista fenomenológica. Essa modalidade de acesso aos participantes possibilita um movimento de compreensão do vivido do ser humano, tal como se apresenta na sua vivência cotidiana. Como modo de acesso ao ser, a entrevista é desenvolvida como um encontro, singularmente estabelecido entre o sujeito pesquisador e cada participante pesquisado. 0 encontro foi mediado pela empatia e intersubjetividade, valendo-se da redução de pressupostos ${ }^{18}$. Exigiu do pesquisador um posicionamento de descentramento de si, para se direcionar intencionalmente à compreensão dos profissionais de enfermagem.

Durante o encontro, o pesquisador precisou: estar atento aos modos de se mostrar do participante entrevistado; captar o dito e o não dito; observar as outras formas de discurso: o silenciado, os gestos, as reticências e as pausas; e respeitar o espaço e tempo do outro. Essa posição de abertura do pesquisador ao outro possibilitou aprimorar progressivamente a condução da entrevista. A entrevista se iniciou pela questão orientadora: Conte-me como é para você cuidar de crianças com doença oncológica avançada. No decorrer da entrevista, a pesquisadora formulou questões empáticas, a fim de evitar induzir respostas, mas destacando questões expressas pelos próprios profissionais que precisavam ser aprofundadas para melhor compreensão dos possíveis significados apontados. Para encerrar a entrevista era desenvolvido um feedback, perguntando se o profissional de enfermagem gostaria de acrescentar algo e agradecendo sua disposição para esse encontro.

Os depoimentos foram gravados mediante consentimento, e a transcrição das entrevistas se deu conforme a fala original, na qual a pesquisadora apontou os silêncios e as expressões corporais observadas durante a entrevista. As entrevistas foram codificadas com a letra $E$ de enfermagem, seguidas dos números 1 a 15.

A análise, pelo método heideggeriano, foi desenvolvida em dois momentos metódicos: análise compreensiva e análise interpretativa ${ }^{17}$. A compreensão vaga e mediana - primeiro momento metódico - constou da suspensão de pressupostos da pesquisadora, ao desenvolver a escuta e leitura atentivas das entrevistas, com vistas a compreender o significado de cuidar de criança com doença oncológica avançada, sem impor-lhe categorias predeterminadas pelo conhecimento teórico e prático. Foram grifadas, nas transcrições, as estruturas essenciais, compondo um quadro de análise. Desse quadro foram constituídas as unidades de significação e o discurso fenomenológico, de modo a compor o conceito vivido, o qual é 0 fio condutor da hermenêutica - segundo momento metódico, interpretado à luz dos conceitos de Martin Heidegger ${ }^{17}$.

0 projeto de pesquisa, aprovado pelo Comitê de Ética em Pesquisa da UFSM/RS sob o número CAAE 0284.0.243.00010, cumpriu com a proteção dos sujeitos quanto aos princípios de: voluntariedade, consentimento livre e esclarecido, anonimato, confidencialidade das informações da pesquisa, justiça, equidade, diminuição dos riscos e potencialização dos benefícios, resguardando sua integridade física-mental-social de danos temporários e permanentes.

\section{RESULTADOS}

0 profissional de enfermagem expressa que o cotidiano de cuidado à criança que tem câncer é triste e desgastante. A parte mais difícil é o envolvimento com o sofrimento das crianças e dos pais. É complicada a não aceitação da doença do filho.

A parte mais difícil é a parte emocional [trabalhar com crianças com câncer] [...] (E1) 
Consigo levar numa boa, não que a gente não se emocione, não que a gente não se apegue, não é isso, muitas vezes, a gente chora com uma criança [...] a gente chora com uma mãe [...] (E2)]

É difícil de tu lidar [...] é impossível não se envolver [...] o mais complicado de lidar são os pais, bem mais difícil a aceitação deles com a doença dos filhos [...] Eu acho difícil de ver o sofrimento deles [...] Tem muita coisa triste aqui. (E3)

Às vezes tu te emociona com algum familiar [...] (E6)

Eujá me acostumei, uma vez que tu se já acostumou, nem se emociona mais tanto, claro que no início era bem triste $[\ldots]$ (E7)

É um desgaste que a gente tem aqui [na unidade de internação], a gente só vê eles [as crianças] entrando na primeira vez ou na recidiva. (E8)

O início foi bem mais difícil, porque tu se deparar com criança com câncer choca. Então, foi bem difícil [...] Às vezes, a gente não está numa fase boa da vida, mais emotiva por algum motivo ou outro, e que te leva a ter mais sofrimento no trabalho. Vero sofrimento dos outros é uma coisa que mexe com a gente $[\ldots]$ (E9)

[...] pelo emocional [é melhor quando eles vão para UTI] mesmo que tu vê o familiar sofrendo, tu vê crianças sangrando, em fase bem terminal mesmo, bem grave em coma [...] (E10)

No começo dá certo impacto, tu chega aqui e é uma criança, e criança é mais complicado, mal começou a vida, é mais complicado, mas a gente tem que tentar aprender com isso. (E11)

[...] não é como tu trata, é como tu te sente frente a essa criança [...] (E12)

Quando a gente vê que aquela pessoa está voltando com uma recidiva, principalmente se são jovens e crianças, a gente pensa: poxa vida! Tu vê que não dá certo e se pergunta: por que que dá certo para alguns e para outros não? Mas, também, eu não passo disso aí, não fico me questionando, vamos seguir em frente, se tem que recomeçar, vamos recomeçar [...] (E14)
[...] eu via o outro lado das crianças, então era um choque dos lados, um choque de felicidade e um choque de dor [...] (E15)

É necessário separar o profissional do emocional. 0 ideal seria que, assim como as crianças e suas famílias, os profissionais também tivessem apoio psicológico, pois devem estar bem preparados e emocionalmente fortes para conseguir trabalhar.

Eu acho que eu tive uma reação muito melhor do que eu esperava [...] eu consegui separar direitinho o profissional do emocional [...] (E2)

Tem que ter o emocional bem preparado [...] é preciso estar bem preparado para trabalhar num lugar assim, tem que ter um emocional muito forte $[\ldots](E 3)$

[...] não temos preparo nenhum específico para cuidar de paciente terminal, a gente não teve isso, cuidado, somente cuidado, carinho e alívio da dor [...] o ideal seria o apoio psicológico da gente também [...] eu tenho feito uma consulta uma vez por mês [com psiquiatra]. Então, fico aquela uma hora assim conversando, que nem eu estou conversando contigo agora, sempre me ajudava bastante $[. .$.$] eu consigo lidar, eu tomo$ antidepressivo também, ainda estou fazendo tratamento, mas eu acho que é por isso que eu tomo, pra não piorar o meu problema. (E5)

Procuro logo me distrair naquela emoção, pensar em outra coisa, pra não levar pra minha vida, tenho conseguido, não sei se daqui uns anos isso tudo vai estar guardado, acumulado e um dia vai explodir. (E6)

O teu emocional tem que estar equilibrando [,] se não tu deixa a peteca cair [...] a gente tem que estar sempre trabalhando com o emocional da gente para não entrar em conflito, e já tem aqueles problemas interpessoais também, que interferem bastante no emocional da gente. (E9)

Pra me proteger, não te envolver emocionalmente, não pensar que aquilo ali [...] (E14)

A gente sofre, a gente chora [pausa] hoje aquela mãe que está ali do teu lado, mas no momento que tu chora, faz com que tu te alivie e a mãe também [...] eu conseguia, pra mim lá [local em 
que trabalhava com crianças sadias] era o meu tratamento, do meu emocional [...] (E15)

Ao significar o cuidado, o profissional de enfermagem descreve o seu dia a dia dentro e fora do hospital. Quando sai do hospital, procura não se lembrar das crianças, se sente aliviado ao sair da unidade. Quando vai para casa, vive a sua vida com seu filho e sua família. Às vezes é impossível chegar em casa e não comentar, para desabafar sobre algum acontecimento marcante do seu dia de trabalho.

Lá fora é uma vida de sonho, quando eu chego aqui eu tô na vida real [...] (E1)

Depois que tu sai daqui [hospital], com relação ao sentimento com os pacientes eu procuro não lembrar lá fora, eu vou pra casa, faço as minhas coisas, e na verdade não é que tu deixa de pensar, mas não com aquela mesma intensidade de quando tu está aqui [...] Olha o alívio de tu estar ali fora, faltando 10 minutos para ti sair, e tu sair da porta pra fora é um alívio muito grande [...] eu vou para casa, vivo a minha vida [...] muitas vezes eu não lembro, não vem na cabeça o que aconteceu ou não aqui, só se é uma coisa que me marcou muito. (E2)

Às vezes, eu procuro, quando saio daqui, esquecero trabalho, vejo o meu filho lá fora, vivo minha vida, familia... É impossível chegar em casa e não comentar alguma coisa, conversar, mas aquilo só para dar uma desabafada, e depois procuro fazer outras coisas. (E3)

Pra mim é normal, eu saio daqui, tenho a minha vida lá fora, não levo nada pra casa, dificilmente eu comento alguma coisa em casa [...] não levo para a minha vida pessoal [...] (E6)

Venho pra cá, cumpro o meu horário, a minha escala, o que eu tenho para fazer eu faço, eu saio naquele portão e pra mim isso aqui morreu, eu esqueço que o hospital existe. Estou assim, tenho a minha vida lá fora, não dá, aí o problema é que no outro dia eu tenho que vir fazer tudo. (E7)

Tento mentalizar coisas boas quando eu boto meus pés aqui dentro, eu tento entrar com o pé direito e penso que eu tenho que ser forte [...] (E9)

Às vezes a gente percebe que está bem esgotado. Claro, tu tem a tua vida lá fora, tu tem a tua vida aqui, né. Mas teve uma época que essa unidade estava [pausa] [suspirou] simplesmente pacientes graves [pausa] graves, e aquilo foi esgotando todo mundo, falta de gente para trabalhar e está bem carregado de trabalhar aqui [silêncio]. (E12)

Sempre, a minha vida inteira, se eu sair daqui, o que aconteceu aqui, a partir do momento que saí da porta do hospital, ficou, não sou nem de comentar, nunca fui, nunca gostei. (E13)

Então, pra mim lá [outro local fora do hospital que trabalhava] era sempre para eu me alimentar, daí quando voltava, não me lembrava tanto da outra criança [com câncer], porque estava em um meio e eu tinha que trabalhar naquele meio, então eu esquecia esse meio de sofrimento [...] Quando a gente chora, existe um alívio maior, porque a gente está compartilhando a dor. Só que a dor dela permanece. A gente... vai para casa. (E15)

Ele consegue separar o trabalho da vida pessoal. Procura não ficar pensativo, esquecer aquilo que aconteceu no hospital e mentalizar coisas boas. Não tem uma fórmula para isso, mas, com o tempo, aprende.

Já aprendi bastante a separar [pausa] por que senão tu enlouquece [...] (E2)

Não tem uma fórmula pra isso [separar o trabalho da vida lá fora] [...] (E3)

Eu consigo, graças a Deus, sair daqui e não ficar tão pensativo lá fora. Faço isso para a minha proteção, se eu começar a me apegar muito, eu sei que vai ser ruim pra mim [...] eu tento não misturar muito as coisas [...] eu consigo até deixar um pouco mais distante, tento não entrar no particular de cada paciente. (E5)

Eu já estou mais escaldada e tu consegue já diferenciar, separar, não levar os problemas para casa. (E10)

Isso hoje eu consigo fazer muito bem, sempre consegui separar, talvez porque eu tinha outro emprego, outro serviço, eu trabalhava com crianças sadias em escolas. (E15)

\section{DISCUSSÃO}

Ao falar do cotidiano de cuidado, o profissional que integra a equipe de enfermagem anuncia como cuida da criança que tem doença oncológica avançada, cuja enfermidade não responde mais aos tratamentos curativos. Ao contar como ele 
mesmo cuida, se mostra como "eu", nesse existir cuidando. Ao se apresentar dessa forma, se revela como ser-profissional-deenfermagem-que-cuida da criança e da família. Ao se mostrar como "eu", assume o lugar de protagonista de suas vivências de cuidado, dizendo que é ele mesmo: como se reconhece, se relaciona e se comporta.

Quando o ser-profissional expressa o cotidiano de cuidado no hospital, mostra-se como ser-no-mundo. Ao atribuir a espacialidade da presença, reconhece-se como ser-com os outros: criança e família. 0 envolvimento com essas crianças e suas famílias gera sofrimento, tristeza e desgaste. Elas foram lançadas naquilo a que elas não puderam escapar: a doença. Esta facticidade em sua rotina constitui-se de um fato do qual não se tem volta, do qual não podem fugir ${ }^{17}$.

0 envolvimento do ser-profissional-de-enfermagemque-cuida desvela o modo de ser-com a criança, a família e consigo ${ }^{17} .0$ ser-com indica a natureza relacional do ser do humano, demonstrando que "todo o ser é sempre ser-com, mesmo na solidão e no isolamento. A pre-sença é sempre copresença, o mundo é sempre mundo-com-partilhado, o viver é sempre convivência"17:319.

Ao significar o cuidado, o ser-profissional mostra-se como ele mesmo é, assume-se na singularidade do modo de ser da autenticidade, em que se apropria de si, isto é, em que se projeta na base de sua possibilidade mais própria. Ao pensar e agir por conta própria, aproxima-se do modo da autenticidade no cumprimento-de-ser-si-mesmo. Essa atitude é considerada autêntica, pois, mesmo de maneira fugaz, a presença recupera a responsabilidade de ser ela mesma.

0 cotidiano assistencial do ser-profissional desvela a preocupação como modo de ser da autenticidade. A preocupação permite a relação com as pessoas, na qual a presença se comporta como ser-com.

No entanto, o ser-profissional está e é "no" mundo no sentido de "lidar familiarmente na ocupação com os entes que vêm ao encontro do mundo"17:152. Essa espacialidade lhe convém e isso só é possível com base no ser-em.

No seu cotidiano assistencial, o ser-profissional revelase presente (-aí) dentro do hospital e comporta-se de diferentes maneiras em seu existir. Na multiplicidade de modos-de-ser, indica continuamente 0 acontecer da história vivida por cada ser. A expressão "em" não configura uma localização espacial, significa: estou acostumado a, habituado a, familiarizado a. A expressão "sou" se conecta a "junto" ao mundo, como alguma coisa que, deste ou daquele modo, me é familiar. 0 ser-em é a expressão existencial da presença que possui a constituição essencial de ser-no-mundo ${ }^{16}$.

Nessa espacialidade apresenta caracteres de distanciamento, que indicam distanciar-se de alguma coisa no sentido de se afastar, sendo essa uma possibilidade para o serprofissional diante de suas vivências e experiências. Assim, ao expressar sentimentos em relação ao seu cotidiano de cuidado, o profissional revela ter que separar o profissional do emocional e ter que estar preparado emocionalmente para conseguir trabalhar na oncologia pediátrica.

As possibilidades do ser-aí-em seu mundo circundante conferem sentido quando o profissional relata que vai para a casa e vive a sua vida lá fora do hospital, mas às vezes comenta sobre algo marcante do seu dia de trabalho. Distanciar-se é, sobretudo, um aproximar-se dentro de uma visão de mundo, em que há um mundo do trabalho e um mundo da vida.

No cotidiano de trabalho, expressa o esgotamento pelo envolvimento com a criança e com a família, pelo avanço da doença e pela necessidade de estar preparado para lidar com os entes que vêm ao encontro no mundo circundante. 0 mundo mais próprio da presença cotidiana é o mundo circundante, essa expressão aponta para uma espacialidade.

Quando refere o alívio ao terminar o turno de trabalho e poder ir para casa, expressando que fora do hospital é uma vida de sonho na qual procura não lembrar coisas do trabalho, o ser-profissional aponta o modo de distanciamento. Essa espacialidade do ser-em indica o "contexto em que de fato uma presença vive"17:105, em que "não apenas é e está num mundo, mas também se relaciona com o mundo"17:64.

A existencialidade, que é constituída pelos atos de cada indivíduo de apropriação e distanciamento das coisas do mundo, designa a existência interior e pessoal. 0 ser humano está sempre procurando algo além de si mesmo, seu verdadeiro ser consiste em objetivar aquilo que ainda não é. 0 homem seria, assim, um ser que se projeta para fora de si mesmo, mas jamais pode sair das fronteiras do mundo em que se encontra submerso. Trata-se de uma projeção no mundo, do mundo e com o mundo, de tal forma que o ser e o mundo são totalmente inseparáveis.

Quando conta que consegue separar o trabalho da vida pessoal e que não tem uma fórmula para isso, mas que, com 0 tempo, aprende, o ser-profissional se mostra no modo temporal. Essa temporalidade não é determinada cronologicamente, pois um mesmo intervalo temporal pode estar relacionado a diferentes vivências e ter diferentes significados. Assim, a vivência deste serprofissional independe do tempo cronológico do tratamento, mas do tempo existencial de relacionamento. Essa compreensão indica o sentido de temporalidade, em que a presença possui uma determinação temporal, "sendo e estando a cada vez no tempo"17:46. As dimensões da temporalidade não são localizações estáticas, pois o passado não é deixado para trás, mantém-se no presente e no futuro. 0 tempo é o ponto de partida do qual a presença se compreende em suas possibilidades.

\section{CONSIDERAÇÕES FINAIS}

0 profissional que cuida da criança que tem doença oncológica avançada se reconhece como ser-no-mundo-com os outros: criança, família e consigo. Essa relação acontece no mundo do cuidado hospitalar e gera sofrimento, tristeza e desgaste. Diante desse cotidiano, o ser-profissional-que-cuida tem a necessidade de separar o trabalho da vida pessoal, revelando sua espacialidade caracterizada pelo distanciamento. 
Essa espacialidade é um modo de ser em que os movimentos de aproximação e de distanciamento integram o cotidiano.

Para o profissional, parece um caminho sem fim, em que o distanciamento se faz necessário para lidar com os desafios e para que, com o tempo, ele aprenda a aliar a objetividade da assistência à subjetividade das relações. No entanto, não se referencia apoio para lidar com os fatos que envolvem o cuidado à criança e à família. Aponta-se para a necessidade do desenvolvimento de estratégias de ação multiprofissional entre a equipe que cuida, considerando que também precisa ser cuidada.

\section{REFERÊNCIAS}

1.Ministério da Saúde (BR). Instituto Nacional de Câncer-INCA. Estimativa 2010: incidência de câncer. Rio de Janeiro; 2009.

2.Ministério da Saúde (BR). Instituto Nacional de Câncer-INCA. Diagnóstico precoce do câncer na criança e no adolescente. $2^{\mathrm{a}}$ ed. Rio de Janeiro; 2011.

3.Rodrigues KE, Camargo B. Diagnóstico precoce do câncer infantil: responsabilidade de todos. Rev Assoc Med Bras. 2003; 49(1): 29-34.

4.Camargo B, Kurashima AY. Cuidados paliativos e oncologia pediátrica: 0 cuidar além do curar. São Paulo: Lemar; 2007.

5.Nacimento LC, Rocha SMM, Ayes VH, Lima RAG. Crianças com câncer e suas famílias. Rev Esc Enferm USP. 2005; 39(4):469-74.

6.Sales CA, Oliveira WT, Violin MR, Schülhi PAP, Tironi NM, Salci MA. Cuidados paliativos em um programa de pós-graduação. Cienc Cuid Saude. 2009; 8(supl.): 47-54.

7.Mutti CF, Paula CC, Souto MD. Assistência à saúde da criança com câncer na produção científica brasileira. Rev Bras Cancerol. 2010; 56(1):71-83.

8.Monteiro CFS, Veloso LUP, Sousa PCB, Morais SCR. A vivência familiar diante do adoecimento e tratamento de crianças e adolescentes com leucemia linfóide aguda. Cogitare Enferm. 2008; 13(4): 484-89.

9.Fontes CAS, Alvim NAT. Importância do diálogo da enfermeira com clientes oncológicos diante do impacto do diagnóstico da doença Cienc Cuid Saude. 2008; 7(3): 346-54.

10.Santos MCL, Pagliuca LMF, Fernandes AFC. Cuidados paliativos ao portador de câncer: reflexões sob o olhar de Paterson e Zderad. Rev Latino-Am Enfermagem. 2007; 15(2): 350-54.

11.Silva MM, Moreira MC. Sistematização da assistência de enfermagem em cuidados paliativos na oncologia: visão dos enfermeiros. Acta Paul Enferm. 2011;24(2): 172-78.

12.Pedro ENR, Funghetto SS. Concepções de cuidado para os cuidadores: um estudo com a criança hospitalizada com câncer. Rev Gauch Enferm. 2005; 26(2):210-19.
13. Costa TF, Ceolim MF. A enfermagem nos cuidados paliativos à criança e adolescente com câncer: revisão integrativa da literatura. Rev Gauch Enferm. 2010; 31(4):776-84.

14.Carneiro DMS, Souza IEO, Paula CC. Cotidiano de mães-acompanhantesde-filhos-que-foram-a-óbito. Esc Anna Nery. 2009; 13(4): 757-62.

15.Lopes VF, Silva JLL, Andrade M. A percepção de profissionais de enfermagem sobre os cuidados paliativos ao cliente oncológico pediátrico fora de possibilidade de cura: um estudo na abordagem fenomenológica das relações humanas. Online Braz J Nurs. [on-line] 2007 [citado 2011 set 5]; 6(3). Disponível em: http://www.objnursing.uff.br/index.php/nursing/ article/view/j.16764285.2007.1155/268

16.Poles K, Bousso RS. Compartilhando o processo de morte com a família: a experiência da enfermeira na UTI pediátrica. Rev Latino-Am Enfermagem. 2006; 14(2): 2007-13.

17.Heidegger M. Ser e tempo , 1. Petrópolis(RJ): Vozes; 2005.

18.Carvalho AS. Metodologia da entrevista: uma abordagem fenomenológica. $2^{\mathrm{a}}$ ed. Rio de Janeiro: Agir; 1991.

19.Boemer MR. A condução de estudos segundo a metodologia de investigação fenomenológica. Rev Latino-Am Enfermagem. 1994; 2(1): 83-94.

\section{NOTA}

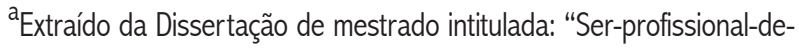
enfermagem-que-cuida da criança que tem doença oncológica avançada que não responde mais aos tratamentos curativos", Programa de PósGraduação em Enfermagem da Universidade Federal de Santa Maria/RS, 2011

Recebido em 27/10/2011 Reapresentado em 19/01/2012 Aprovado em 09/02/2012 